NOTE: This is an Accepted Manuscript of an article published by Taylor \& Francis in American Journal of Bioethics on available onlinein November 2014 :

http://www.tandfonline.com/ DOI:10.1080/15265161.2014.957416

\title{
Ethical justifications for access to unapproved medical interventions: an argument for (limited) patient obligations
}

\section{Abstract:}

Many healthcare systems include programs that allow patients in exceptional circumstances to access medical interventions of as yet unproven benefit. In this paper we consider the ethical justifications for - and demands on - these special access programs (SAPs). SAPs have a compassionate basis: they give patients with limited options the opportunity to try interventions that are not yet approved by standard regulatory processes. But while they signal that healthcare systems can and will respond to individual suffering, SAPs have several disadvantages, including the potential to undermine regulatory and knowledge-generation structures that constitute significant public goods. The 'balance' between these considerations depends in part on how broadly SAPs are used, but also on whether SAPs can be made to contribute to the generation of knowledge about the effects of health interventions. We argue that patients should usually be required to contribute outcome data while using SAPs.

Keywords: healthcare delivery; research ethics; experimental therapies; regulatory issues; end-of-life issues; patient rights; special access. 


\section{Introduction}

Special access programs (SAPs) allow access to medical interventions (drugs and devices) that lack formal approval for widespread use. SAPs exist in different forms in many countries, variously known as early access, expanded access, managed access, special access, compassionate use, or named patient programs. The medical interventions usually lack formal approval because they have not (yet) been evaluated to the satisfaction of regulatory authorities and so are "experimental" or "investigational" to some degree. SAPs make these interventions available in several circumstances. They may be used to offer new interventions as a "last chance" to patients at risk of death or serious disability, who lack other treatment options. They can make interventions available for the treatment of rare (orphan) diseases that affect such small numbers of people that clinical trials to assess efficacy are not feasible. They may also enable access to treatment when an intervention lacks approval within a country whose market is too small to provide an incentive for manufacturers to seek registration. Our focus is on the use of SAPs for early access to new potentially life-prolonging or disability-preventing interventions for relatively common conditions. ${ }^{1}$

We argue that SAPs can be ethically justified, largely on grounds of compassion. However, SAPs bypass the usual systems for regulating access to medical interventions. In the context of general prohibitions against use until safety and efficacy are established, SAPs respond on a case by case basis.

${ }^{1}$ These schemes are distinct from the phenomenon of off-label use of interventions, which we do not seek here to investigate. We note, however, that offlabel use raises some overlapping issues with SAPs, as it also involves providing an intervention for an indication for which evidence is lacking. See, e.g., Largent (2009); Ghinea (2012); Isbister et al (2009). 
Though ethically justifiable, they have an individualistic orientation that is in tension with population-based rationales for regulating access to medical interventions. Further, SAPs may weaken regulatory processes insofar as they bypass standard procedures for evaluation-before-approval, and can delay or impede the development of robust evidence about safety, efficacy and effectiveness, for example by undermining recruitment into research trials. Thus, somewhat paradoxically, SAPs may compromise solving the very problem that necessitates their existence: SAPs respond to the need to allow access to interventions about which we lack knowledge, but to the extent that they undermine the generation of that knowledge, they may reinforce the very problem of knowledge deficits that gave rise to them. Thus SAPs are problematic given their capacity to threaten regulatory protections and the development of medical knowledge. We argue that to overcome this problem, SAPs should play a mandated role in knowledge generation. However, such a move imposes an obligation on patients participating in SAPs to agree to data collection.

In section 1, we examine the population-based moral foundation for regulating access to medical interventions, and the rationale for SAPs within the context of regulated access. In section 2, we review SAPs in the USA and Australia, and highlight key similarities and differences across international SAPs. In section 3, we review potential benefits and harms of SAPs and further our critical assessment of their ethical justification. In Section 4 we argue that the ethical costs of SAPs should be balanced by mandatory data collection. In section 5 , we recognise several challenges in developing systems for such data collection and use, noting that these are broader challenges related to an increasingly blurred distinction between research and practice in healthcare.

\section{The challenge of SAPs to the regulation of medical interventions}

The primary aim of regulating access to medical interventions is to prevent harm. Historically, many developments towards today's regulatory approach 
occurred in response to problems that arose from the use of untested, adulterated, unsafe, or simply ineffective interventions. For instance, after a "tonic" containing diaethylene glycol caused over 100 deaths in 1937, the Food, Drug and Cosmetic Act introduced the need for pre-marketing approval of medicines by the Food and Drug Administration (FDA) (FDA 2013). In the 1960s, birth defects resulting from the internationally widespread use of thalidomide to treat morning sickness prompted a strengthening of requirements for evidence of safety and efficacy prior to approval being granted (Rago and Santoso 2008,65-66). Such public health disasters demonstrate the need to protect the public from unsafe medical interventions. The requirement to demonstrate efficacy also protects the public from the financial and opportunity costs associated with use of ineffective interventions. Today most countries require evidence of safety and at least minimal efficacy for approval of medical interventions, though standards differ by jurisdiction and type of intervention. $^{2}$

Regulation fulfils a further important function regarding research. Manufacturers are required to demonstrate that their products meet standards for safety and efficacy in order to market those products. This creates an incentive to develop and test products, undertake medical research, and contribute to medical knowledge (Shorr 1992, 2). ${ }^{3}$

Justifications for the regulation of new medical interventions draw on population-focused rather than individual approaches to ethics, taking account of the potential for harm of allowing unrestricted access to the goods in question; and of the opportunity costs should ineffective interventions be

${ }^{2}$ Many jurisdictions having a lower evidentiary standard for devices compared to drugs. Pharmaceutical agents typically go through four phases of testing: phase I trials assess a drug's safety, usually among healthy volunteers; phase II trials assess efficacy in a small cohort of affected patients; phase III trials test efficacy in a larger cohort (often as a randomised controlled trial (RCT)); phase IV trials occur post-approval and examine long-term safety and effectiveness.

${ }^{3}$ Although we note the growing criticisms of industry funded research and its potential to skew the evidence base. See, e.g., Lundh et al (2012). 
approved. Regulators adopt a version of the precautionary principle: that where novel technologies have potential, if uncertain dangers, it is preferable (or at least permitted) to ban those technologies rather than run the risk of the dangers materialising (Munthe 2013). There is a presumption towards restricting new medical interventions on the grounds of their potential for causing harm, and the onus on overcoming the restrictions is placed on the manufacturers of the products (Meyerson 2013, 612). Additionally, the focus on research evidence of efficacy has the potential to lead to more equitable and just healthcare provision (Shorr 1992, 4), especially where such evidence is used to mandate access.

However, a population-based approach to regulation can be at odds with the more individualist focus of medical ethics, which conventionally emphasises respect for autonomous choices, and calculations of benefits and harms given the patient's particular circumstances and preferences (Beauchamp and Childress 2013). This tension has come to prominence in cases where individuals or groups seeking access to particular unproven treatments have challenged the moral (and legal) justification for regulation, such as in the recent case of Abigail Alliance v. von Eschenbach. The Abigail Alliance was founded by Frank Burroughs, whose daughter Abigail had a squamous cell carcinoma of the head and neck unresponsive to chemo- and radiation therapy. Burroughs had unsuccessfully attempted to obtain experimental drugs (genfitinib and cetuximab) being tested in clinical trials for which Abigail was ineligible (Jacobsen and Parmet 2007, 205). In 2005 the Alliance submitted a citizen petition proposing changes to enable access to any treatment after phase I (safety) trials, asserting that access to unapproved interventions is a "civil and human rights issue" (Abigail Alliance 2003, 7). The Alliance then sued the commissioner of the FDA and the secretary of the US Department of Health and Human Services. After two appeals, the suit was dismissed in 2007 (Jacobsen and Parmet 2007, 205; Falit and Gross 2008). As well as considering legal bases for recognising a right to access unapproved medications, the arguments in the case focused on the potentially negative impact of this alleged right on the rights of others - in particular, its potential to 
undermine usual regulatory restrictions, and to interfere with medical research (ASCO 2007; Bender et al 2007, 3; Robertson 2006; US Court of Appeals 045350).

It can be helpful to think of the aims of regulation of access to medical interventions as 'corporate' goods. A corporate good is a kind of collective good, distinguishable from an 'aggregative' collective good. Aggregative goods benefit a number of particular individuals but their overall benefit is limited to the sum of these individual benefits. In contrast, the value of corporate goods extends beyond the sum of benefits provided to particular individuals; they are of value to the whole population rather than only those receiving individual benefits (Widdows and Cordell 2011, 17). Public protection from unsafe or ineffective medical interventions, and advancement of medical knowledge, are corporate goods, because even those who do not actually receive any particular medical interventions in the course of their lives benefit from the existence of such interventions in their society. Safe and effective interventions promote the overall health of a community, and all individuals benefit from living in a community that has higher standards of health, whether or not they personally are recipients of any particular intervention.

However, as noted in the above discussion, tensions can emerge between protecting corporate goods through population-based approaches to regulation, and the needs or preferences of individuals. SAPs facilitate access by allowing exceptions to the usual regulatory procedures, typically when patients lack alternative treatment options and, without further intervention, are at risk of death or serious disability. When individual patients are in such straits, a population-focused approach to regulating access to interventions of unknown safety and efficacy can seem unnecessarily harsh. The risks and benefits of using unproven interventions for individuals faced with life-threatening illnesses differ considerably from those at a population level, and those individuals' attitudes to the uncertainties and trade-offs in decisions about using unproven interventions are likely to be shaped by their circumstances. In 
these cases, seeking even a slim chance of improvement is a rational choice (Edwards 2006, 83). Restricting access may increase suffering for those who feel they have nothing to lose, whether or not the intervention works, and so may be considered to cause harm disproportionate to the potential harms arising. Compassion in these circumstances seems to urge allowing access.

This is not to say that regulation should never apply to patients who are terminally ill or face serious disability: regulation seeks to protect all patients from the risks associated with unproven interventions. ${ }^{4}$ But in the usual case, the reason to restrict access to unproven interventions is the avoidance of unknown and potentially widespread harms; there is no sufficient evidentiary basis for their use or knowledge of their effects, so a precautionary principle prevails. This principle loses at least some of its moral force in cases where patients are otherwise at high risk of death or serious disability.

Although the individualistic focus of SAPs is at odds with the population basis for regulating access to medical interventions, SAPs enable access as exceptions to the norm. They do not replace the norm, and if the exceptions are rare and made in clearly exceptional circumstances, they do not compromise the reasons for restricting access to any significant degree. The interventions remain generally unavailable and general public protection from unsafe or ineffective interventions continues. As such, the incentive to develop the necessary evidence base for marketing approval remains in place. The compassionate response that SAPs allow can thus be taken to justify exemption from the usual precautionary approach to the risk of using experimental interventions.

${ }^{4}$ In the US, a series of legal cases in the 1970s dealt with this issue. See Supreme Court of United States Case 78-605 (1979). 
But to the extent that SAPs jeopardise the corporate goods which are promoted and protected by general access being subject to regulation, the balance shifts and SAPs become problematic. In recent years, many countries have introduced SAPs, and others have reformed their systems to further ease access to unapproved interventions for patients. These expansions increase the possibility that SAPs could undermine or compromise the aims of regulation.

One form of expansion is encouraged by calls to enable access at earlier stages of drug development, when potential risks and benefits are less certain (Abigail Alliance 2003). Further scope for expansion exists because the typical criteria for SAP access - risk of death or serious disability and lack of other treatment options - are open to interpretation (Caplan 2007, 2; Falit and Gross 2008, 2795). Individual clinicians vary in their assessments of risk of death; what counts as a serious disability is not clearly defined; and even whether or not particular patients lack other treatment options can be a matter of opinion. It is thus important to assess carefully the implications of SAPs and the potential for undermining the aims of regulation. The following section examines SAPs internationally, before we turn in section 3 to critically assess the justifications for SAPs.

\section{Key features of SAPs}

Table 1 provides a summary of selected SAPs in Northern America, Australia, and Europe. ${ }^{5}$ Here we briefly review American and Australian systems as examples.

${ }^{5}$ Complete information was not readily available for all countries. Note that in some locations (including the UK) regulations have recently been under review. 
[Insert Table 1 here]

In the USA, access to unapproved medical interventions has been possible since the inception of the FDA, although early procedures were somewhat informal. In 1962 "investigational new drug" (IND) procedures were introduced. In addition to INDs for clinical trial purposes, "orphan drug" or "compassionate use" INDs could be used to obtain new drugs or devices for individual patients or small cohorts (Institute of Medicine 1991, 6-9). In the 1980s, efforts were made to ease access to experimental interventions, largely in response to the spread of HIV. The introduction of "treatment" INDs allowed physicians to obtain experimental drugs for specific patient cohorts when: no alternative treatment was available; clinical trials were underway or complete; there was some clinical evidence of safety and potential effectiveness; and a treatment protocol had been pre-approved by the FDA (Institute of Medicine 1991, 14-17). ${ }^{6}$

These SAP programs vary in their requirements for adverse event reporting and the collection of other outcome data. In some cases, physicians must provide regular patient status reports to manufacturers in order to continue to receive supplies (Institute of Medicine 1991, 30; 35). However, using SAPs to collect data has been controversial within the USA, with concerns about both the evidentiary value of such data and the potential to undermine clinicians' participation in research (Institute of Medicine 1991, chapter 4).

\footnotetext{
${ }^{6}$ For more detail on these and related programs see Edwards (2013); Institute of Medicine (1991); Schuklenk and Lowry (2009).
} 
Changes to FDA rules in 2009 led to a simpler notification scheme for individuals or small cohorts, leaving intact more stringent FDA approval requirements for larger cohorts. SAP access was extended to those with any serious condition, as opposed to only terminally ill patients (Young 2009, 478), and evidentiary requirements were lowered for access in cases of "immediately life-threatening diseases or conditions" (FDA 2009, 40900). Assessment (by the FDA) is case-by-case. Ethics (IRB) approval is required but, along with reports to the FDA on treatment outcomes, may be bypassed in some emergency situations (for more detail see Dresser 2006; FDA 2009, 40905; Leonard 2009).

In Australia, unapproved medical interventions may be accessed for individuals through the Special Access Scheme (SAS). In cases where a patient is at risk of death, the Therapeutic Goods Administration (TGA) requires notification from the physician; in other cases the TGA must review and authorise the intended use (TGA 2009, 8). Adverse event reporting is required, but no other data need be collected, and there is no requirement for ethical review or approval (TGA 2009). There are few restrictions on which interventions are accessed via SAS as the system is driven by clinician requests.

Australia also has an Authorised Prescriber System that allows individual practitioners to prescribe unlicensed pharmaceuticals for specific indications to patient cohorts. For 'authorised prescriber' status, TGA approval is required, and there are stricter procedural demands than for individual patient SASs. These include approval from a human research ethics committee (HREC), use of informed consent protocols approved by the HREC, and reporting of patient outcomes to the HREC (TGA 2004). Patient outcomes are not analysed for knowledge generation purposes.

Despite the similarities of these, as well as the other programs noted in Table 1, there is significant variation between SAPs. The role of the relevant regulatory authorities range from no involvement at all, to receiving notifications, to reviewing and authorising particular uses. Some SAPs limit access to patients ineligible for clinical trials, and there are differences in the phase of development the intervention must have reached. Costs are variously paid by 
patients, manufacturers, national health bodies or insurance companies. Some SAPs require ethical oversight, others do not. Some of these differences may reflect contextual differences across jurisdictions, such as the overall availability of clinical trials in which patients might participate, the presence or absence of universal healthcare, and the scope of the remit of the regulatory body. ${ }^{7}$

While most programs mandate adverse event reporting, this is usually no more onerous than adverse event reporting in routine clinical practice. In many cases therefore, information about adverse events or other outcomes is not systematically collected for use either by manufacturers or regulators. Some SAPs require quite comprehensive collection of outcomes data but it is often unclear whether and how these data are collated or analysed, shared or used for knowledge generation. Manufacturers may consider such data to be 'commercial in confidence', which can frustrate attempts to monitor or collate data about interventions accessed via SAPs. As a result, current SAP systems do not contribute systematically to the generation of medical knowledge about the safety and effectiveness of new interventions.

\section{Ethical considerations in the use of SAPs}

Here we examine the implications of SAPs for stakeholders including patients, clinicians, manufacturers and society, to assess their ethical justifiability. Despite their benefits, SAPs pose a risk to current regulatory structures. In section 4 we argue that this risk should be alleviated by the use of SAPs for knowledge generation.

${ }^{7}$ We lack the space here to comment in detail upon the effects of the differing rules across international jurisdictions. In addition, data on the prevalence and kinds of use of SAPs is unobtainable in many instances, hindering development of further detailed analysis of this kind. 


\section{Patients}

A major justification for SAPs, incorporated within the idea that they are expressions of compassion, is their potential to provide benefits to individuals who have run out of other options. Patients receiving drugs or devices through SAPs may obtain gains in longevity and/or health. However, we know little about the proportion of interventions accessed through SAPs that is subsequently shown to be safe and effective, and eventually approved. Estimates vary depending on the novelty of the intervention and the stage of evaluation; overall, new chemical entities have an $8 \%$ chance of eventual approval, but this is much higher in later stages of development (DiMasi et al 2003). ${ }^{8}$ Patients may also value the opportunity to pursue further chances of treatment, and to avoid the potential regret of not having done so, irrespective of any health gains (Ross 2009, 136). The signal that SAPs send that national bureaucracies can and will respond compassionately to individual cases of medical distress may itself comfort patients and their carers.

Notwithstanding actual and possible benefits, there are potential harms to patients from receiving experimental interventions, which may neither improve symptoms nor extend life, and could cause unpredictable ills. ${ }^{9}$ Depending upon the stage of development of the intervention, population or individual level information on safety, efficacy, and guidance about dosage amounts and schedules may be severely limited (ASCO 2007, 18). However, as noted above, these risks may be discounted in contexts where patients face death or serious disability without intervention.

\footnotetext{
${ }^{8}$ DiMasi et al (2003) calculated that new experimental drugs had: $40 \%$ probability of moving from initial IND application to phase I trials, $75 \%$ probability of progressing from phase I to phase II trials, $48 \%$ probability of moving from phase II to phase III trials, $64 \%$ probability of moving from phase III trials to an application for approval, and a 90\% chance, once submitted for approval, of receiving it.

${ }^{9}$ Of course, these are possible outcomes of any intervention - approval by a regulatory body does not ensure that an intervention will do more good than harm in individual cases.
} 
Although patients may wish to exercise their own judgement about receiving unapproved interventions, and have, via the internet, greater access than ever before to information about potential interventions, they may struggle to make judicious "all things considered" decisions about their healthcare. There is a risk that some patients will choose to receive SAP interventions because they are in a desperate situation and harbour incorrect or unrealistic expectations of experimental interventions (Bedlack 2011, 313; Bender et al 2007, 3; Bristol 2007, 816; Caplan 2007, 2; Schuklenk and Lowry 2009, 14-15; and cf the 'therapeutic misconception' within research trials; see Appelbaum 1982; Cholst 2013). The existence of SAPs might even contribute to overoptimistic expectations, if they are misperceived as official sanctions implying that the experimental interventions thereby accessed are likely to work. Or patients may feel unable to refuse even the slimmest chance offered by further treatment options through SAPs, in one form of what has been called a "technological imperative" (a sense that every possible avenue offered by new technologies must be explored [Hofmann 2002, 683]). While some individuals may benefit, the technological imperative can encourage the use of new interventions as an end in itself, with the danger that novel options are pursued even when they have no benefits, or are detrimental (Hofmann 2002,679).

Thus although SAPs seem to increase patient choice, they can also narrow it. This is of particular concern when patients perceive pressure from (or wish to avoid disappointing) family members who want them to keep "fighting" (Epstein and Entwistle 2013). The pursuit of experimental interventions through SAPs can foster unwarranted hope and distract from other forms of help and support such as palliative care, or grief counselling for family members. It is possible that SAPs increase patients' vulnerability to harm if manufacturers exploit the lack of other treatment options (ASCO 2007, 23), or clinicians pursue particular interventions based more on a desire to pioneer something new than on considerations of patient welfare.

Some patients may value SAPs as an opportunity to receive an experimental intervention without having to participate in a formal clinical trial. 
Although the intervention itself may not differ whether accessed via a clinical trial or by SAP, trials often entail uncertainty about receipt of the desired intervention (due to randomisation), and may require patients to see different or additional clinicians, or engage in potentially burdensome follow-up protocols. Patients in SAPs are not subject to the protective oversights and ethical review guaranteed to clinical trial participants (Edwards 2013, 3).

Realising the above benefits for patients provides the major justification for provision of SAPs. And despite the risks for individual patients, given that they face dire consequences and lack other treatment options, protection from experimental interventions may be waived for these particular individuals. However, the more extensive the use of SAPs becomes, the greater their potential to undermine the aims of regulation, thereby challenging beneficent and compassionate justifications for their existence.

Clinicians

The discretion offered by SAPs supports the epistemic authority of individual clinicians regarding what is best for their patients, and allows clinicians to try further interventions for patients without alternative therapeutic (as opposed to palliative) options. It is unclear how often SAPs are pursued primarily by clinicians rather than patients (or their families); but while clinicians will vary in terms of their inclination to suggest, promote or support the use of particular experimental interventions for individual patients (via SAPs or otherwise) some clinicians may value the opportunity to further exercise their medical judgement, pioneer new uses of technologies or feel 'up-to-date' with innovations in practice.

However, clinicians risk the possibility of liability issues or damage to their reputation if patients are harmed (although when SAPs are used for very sick patients, poor outcomes will inevitably occur, lessening the likelihood of complaint). It is also possible that if use of SAPs becomes widespread, clinicians may be subject to increasing pressure from patients seeking particular as yet unproven interventions, and find themselves "caught between 
patient demands for ineffective or dangerous pharmaceuticals and physicians' ethical obligation to do no harm" (Jacobsen and Parmet 2007, 207; see also Leonard 2009, 274). Clinicians too may feel the force of the technological imperative. Thus SAPs may have complex and unpredictable effects on the framing and freedom of clinical decisions.

\section{Developers and manufacturers}

Regarding developers and manufacturers, the main issues raised by SAPs are commercial, as SAPs may enable new treatments to reach market early, prior to full regulatory approval. Manufacturers may use SAPs to unofficially launch new products, spreading awareness and generating demand among patients and clinicians prior to approval (Bates 2008). Thus, providing a product through a SAP may enable manufacturers to increase profit from a particular intervention if it subsequently gains approval. Pre-approval access may also generate support and anecdotal evidence to fuel campaigns to fast-track general access, or to maintain continued use of a product accessed by SAP if subsequent research results fail to meet criteria for full approval. ${ }^{10}$

However, SAPs may carry financial costs for manufacturers, where direct payments are not permitted, and may become more costly should use of SAPs expand (FDA 2009, 40930). Manufacturers have reportedly been reluctant to provide some unapproved products via SAPs due to their potential liability, should interventions turn out to be harmful (ASCO 2007, 24; FDA 2009, 40907). ${ }^{11}$ There is also the potential for negative publicity; a well-publicised adverse event could lead to lack of support for an otherwise promising intervention (Bedlack 2011, 313; Kelly 2009, 36; Ross 2009, 137). Overall, SAPs may

\footnotetext{
${ }^{10}$ Bevacizumab (Avastin), for example, received accelerated approval by the FDA in 2008 for breast cancer, despite the lack of evidence that it extended life. When this approval was revoked in 2011, people who had used it previously protested vigorously (Carpenter et al 2011).

${ }^{11}$ To our knowledge this liability has not yet been legally tested in any country.
} 
provide developers and manufacturers with a way of avoiding presenting evidence of safety and efficacy to regulators, and building unwarranted support for untested products. This is potentially one of the major ethical harms of SAPs.

Society

Societal advantages of SAPs, as discussed above, include providing a mechanism to recognize that general protections for the public afforded by the regulation of medical interventions may be circumvented in particular cases, thereby allowing a society to act compassionately in cases of individual distress. But SAPs impact upon societal interests in safe and effective healthcare provision, may jeopardise beneficial and fair healthcare provision, and undermine contributions to medical knowledge to the benefit of all current and future patients.

SAPs may impact on the equitable provision of healthcare. As noted above, the typical criteria for accessing interventions via SAP are open to interpretation (Caplan 2007, 2; Falit and Gross 2008, 2795). This can be problematic, as illustrated in the ongoing use in Australia of a SAP to provide naltrexone sustained-release implants as a treatment for opioid addiction. In order to access the naltrexone implants, opioid-dependent patients are classified as being at increased risk of death. This is consistent with epidemiological data comparing mortality among heroin users to the general population. However, not all clinicians agree that opioid addiction constitutes a life-threatening situation of the relevant kind (RACP 2013, 6). And since there are other treatments available for heroin dependence, the use of naltrexone implants through the SAP also requires a likewise contested judgement that such treatments are not suitable for these particular patients. The end result is that individuals' access to naltrexone is variable, and at the discretion of their clinicians, and may be inequitable as patients with similar levels of morbidity and distress are treated differently. The social inequalities that pattern much of routine clinical practice are likely to be repeated in access to 'special' status interventions, exacerbating issues of equity. This may be particularly 
true in cases where SAP interventions are not funded by governments. Patients with greater social and economic resources are likely to be more able to pursue SAP interventions by virtue of their capacity to 'shop around' for a physician willing to authorize particular unapproved interventions and to fund these.

Potential cost burdens to society are difficult to predict as the funding implications of SAPs vary by location and program. Where healthcare payment systems are structured around evidence of safety, efficacy and cost-effectiveness, SAPs have the potential to open the door to costly and unproven interventions, thereby subverting attempts to contain costs based on sound reasoning and evidence. Supplying unproven interventions entails opportunity costs; manufacturers may not develop alternative options and governments have less to spend on more effective interventions. Increased use of unapproved interventions may also support a technological imperative within society more generally, increasing unnecessary or unhelpful uses of new medical technologies (Hofmann 2002). And, should trials subsequently reveal risks or lack of efficacy/effectiveness, or manufacturers fail to seek full regulatory approval, there may be difficulties in managing supply, especially for individuals who believe that they have benefitted from the intervention.

Perhaps the most concerning consequence for society is that, if use of SAPs becomes extensive, this may compromise the corporate goods of public protection and the development of medical knowledge. Patients may be discouraged from participating in clinical trials, or manufacturers from running trials, thereby slowing or limiting knowledge generation or threatening current evidence-based norms for establishing the safety and efficacy of interventions (ASCO 2007; Bedlack 2011; Bender et al 2007; Chahal 2010, 367; Davis 2006; Falit and Gross 2008; Jacobsen and Parmet 2007; Robertson 2006). In the 1980s, a significant slowing of recruitment to trials of dideoxyinsoine as a treatment for HIV was attributed to the wide availability of the drug through a SAP. In the 1990s, autologous bone marrow transplant for breast cancer was frequently performed outside of trials, delaying trial recruitment 
and the progress of research; it was eventually found to be no more effective than other standard treatments (ASCO 2007, 19). A recent study found that RCTs in which the interventions could be accessed (generally) off-label had longer times to completion, and lower participant accrual than RCTs in which the intervention was available only through trials (Hamilton et al 2010). SAPs could have negative effects on the scientific integrity of trials in less obvious ways, for instance patient and clinician support generated via a SAP might influence trial design and increase the likelihood of confirmation bias among researchers (in non-double-blinded trials) (Chahal 2010, 369; Schuklenk and Lowry 2009, 18). ${ }^{12}$

Some countries, such as the USA, make ineligibility for clinical trials a condition of receiving interventions through a SAP to guard against such eventualities (particularly given that some patients may prefer SAP to trial access, as noted above). It is not clear how effective this restriction can be. Patients may for instance, render themselves ineligible for clinical trials of new cancer therapies by undergoing one round of chemotherapy (ASCO 2007, 21-22). The restriction also raises other concerns, such as whether it unduly influences patients' decisions about whether or not to participate in a trial, thereby compromising the value of consent (Schuklenk and Lowry 2009; and see Edwards 2006). ${ }^{13}$

This section has canvassed the benefits and harms of SAPs. While there are significant potential harms to the widespread use of SAPs, we believe

${ }^{12}$ This could have a further implication for equity, as burdens of research participation may come to fall disproportionately on the disadvantaged if experimental interventions can be accessed without cost via trials compared with self-funding the same intervention via a SAP (Schuklenk and Lowry 2009, 16). Even where manufacturers are only able to charge for costs for interventions accessed via SAP, these costs may be higher than some patients can readily afford (Edwards 2006).

${ }^{13}$ For these reasons we do not consider making ineligibility for trial participation a condition for SAP use a preferable option. However, we consider our below proposals for collection of data from SAP usages to be another way to address these issues. 
that on balance, they are ethically justified on the grounds of compassion, albeit it with some caveats. SAPs provide a response to the ethical imperative to act compassionately towards individual cases of distress, representing an exception to the generally applicable precautionary principle governing regulation of medical interventions. This compassionate response is in itself of benefit to individuals, in addition to any specific health gains. As such SAPs can be considered to provide society with an aggregative collective good; that is, the sum total of the benefits from SAPs accruing to individuals. However, this justification is largely individualistic, and in tension with the justifications for regulating access to medical interventions. Regulation also benefits individuals in terms of the safety and efficacy of any medical interventions they may access, but as we claimed above, regulation also promotes corporate goods, which benefit us all. As such the aims of regulation can be considered to 'trump' those of SAP provision where they are directly in tension. Therefore, SAPs should not jeopardise the formal channels for generating medical knowledge, to the detriment of future patients; nor be used so widely that they undermine the role of public protection played by restrictions on access to unproven interventions. Where these occur as a result of SAPs, their individualistic justification is no longer adequate. We argue below for a way to help ensure that this does not occur, based on the recognition that SAPs themselves represent a lost opportunity for society to obtain medical knowledge. As with any research, the knowledge benefit accrues whether or not the interventions turn out to be safe or effective.

\section{Ethical obligations to knowledge generation}

Using SAPs to generate information on the experimental interventions involved would help to overcome or ameliorate some of the disadvantages discussed above, and tip the ethical balance in favour of SAPs. 
There are several reasons to collect outcomes data systematically where SAPs are in use. First is simply that to fail to do so wastes valuable opportunities. The numbers of interventions supplied and patients treated under SAPs is largely unknown, but in some cases may exceed numbers in phase I and II trials for safety and indicative evidence of efficacy (ASCO 2007, 20). Every patient using an unproven medical intervention generates potentially useful information about its therapeutic and side-effects. Harnessing this information for knowledge generation may contribute to faster and more robust answers about safety and effectiveness. Of course, such data would be collected in the absence of a control group or other methodological rigours of clinical trials. It thus has limited capacity to inform about efficacy, and would require careful evaluation and analysis in order to address potential biases (including manufacturers or clinicians seeking to generate favourable data by selecting patients most likely to do well on the intervention). Nonetheless, in some cases at least, such data may be comparable to data collected via patient registry databases, or retrospective cohort studies.

Data collected from SAPs could therefore, at least in part, expedite filling the knowledge gaps that necessitate their existence. Faster generation of evidence might either reduce the numbers of future patients who are harmed by interventions that are ultimately found to be unsafe or ineffective, or increase the numbers of future patients who can confidently access effective interventions. Data collection might also inhibit the routine use of SAPs to access particular medical interventions that lack an evidence-base.

Second, if SAPs can generate usable data, this addresses the concern that SAPs may weaken our systems for developing and testing new medical interventions, and more generally, knowledge generation. If data is collected from SAPs (and perhaps even pooled from SAPs worldwide), then any damage done to the progress of medical research by SAPs would at least be partly compensated for, even if the data accruing from SAPs is not of the same quality as that collected via clinical trials. In addition, some SAPs provide access to interventions for which there are no trials; data from such SAPs would represent 
a new addition to the evidence base. SAPs might also provide data on patient populations who are not often included in formal trials, and on orphan drugs or treatments for rare conditions, thus contributing to filling important knowledge gaps. Harnessed for data collection, SAPs could thus contribute to, rather than undermine, the generation of medical knowledge.

Above we claimed that medical knowledge can be considered a corporate good: we all benefit from living in a community able to provide the safe and effective healthcare made possible by research. Since this corporate good may be damaged or undermined by SAPs, collecting data on interventions accessed through SAPs, and harnessing these data for knowledge generation, is appropriate in order to limit such damage. And, given that patients are being permitted to circumvent systems that serve important corporate goods, it is legitimate to expect patients and those treating them to limit any negative social implications of so doing. Therefore, when using SAPs, patients, clinicians and manufacturers can be considered to have an obligation to contribute as far as reasonably possible to knowledge generation. ${ }^{14}$

We recognise that patients (or their families) might object to having their data collected, and it could seem unfeeling to expect this of patients who are already very sick. But the burden on patients and families of contributing to data collection when accessing interventions via SAPs is likely to be quite limited. Data collection systems for interventions accessed via SAPs could use a registry-type model based on data routinely collected from each patient on key outcomes, including but not restricted to serious adverse events. This kind of data can be de-identified and often based largely on clinical observation (Evans et al 2013). Indeed, clinically observed outcomes data may already be collected by manufacturers in some cases. Additional data on patient-reported

\footnotetext{
${ }^{14}$ With regard to patients, Harris (2005) and Schaefer et al (2009) use similar considerations to draw stronger conclusions than we do here.
} 
outcomes are likely to be useful, but we would see these as discretionary for seriously ill patients and families depending upon their inclinations and capacities. SAP-derived data could supplement that obtained through trials, or provide relevant information about safety and effectiveness where trials have not yet commenced (depending on the limitations of this data in each particular context). The feasibility of collecting data through SAPs is demonstrated by a number of small studies (e.g., Atkinson et al 2007; Barnabe et al 2012; Beran and Sheehan 1996). Wicks et al (2010) demonstrate the use of an online patient-supported database to collect data on the outcomes of unapproved interventions for amyotrophic lateral sclerosis (see also Chahal 2009, 369).

Data collection and analysis helps to redress some of the ethical concerns about SAPs. In addition to addressing concerns about undermining medical knowledge and regulatory systems for public protection, this approach may assuage the worry about SAPs raising unwarranted hopes or misperceptions of likely benefit among patients, as data collection emphasises to patients the experimental nature of their treatments. The additional small administrative burden involved in data collection from SAPs might help to prevent their becoming more widely used than is appropriate. Data collection might also prevent overuse of SAPs for specific interventions; for instance, a threshold number of orders could be specified, above which ethical review is triggered. And hopefully, in the longer term the data collected from SAPs will help to ameliorate the difficulties related to decision-making in situations of therapeutic uncertainty.

\section{SAPs, research, and practice}

Our proposal is not without other challenges. Our argument above focuses on ethical reasons to pursue data collection through SAPs. But there are further 
practical issues and regulatory challenges to consider. For instance, who would fund data collection, and be responsible for data analysis and for drawing conclusions? Pre-approval data collection is generally the responsibility of manufacturers, and data may at this stage be their intellectual property. This raises issues of whether manufacturers would come to regard such programs as an investigatory alternative to running clinical trials; the evidentiary status of the data for approval processes; and what research-like participant protections should be used in SAPs. International data collection would provide the most comprehensive and useful results, but this may require negotiating international laws. It is beyond our present scope to offer a fully developed account of the practicalities of collecting, collating and analysing data from SAPs. However, the responsibilities for using the data might be distributed amongst the various stakeholders. For example, analysis of SAP data might become a standard part of the development of Phase 3 trials.

Not all of the issues raised above can be resolved by data collection. Generating robust and generalizable conclusions from even high quality data from patients who receive drugs or treatments for rare diseases may not be feasible, thus will not obviate the need for orphan drug SAPs. Increased regulation may discourage engagement with SAPs by manufacturers and clinicians (Institute of Medicine 1991, 30-31). Protections for patients must be balanced against the need to ensure sufficient incentives for manufacturers both to participate in SAPs for patient access, and to run formal clinical trials.

While we recognise the importance of the above challenges, we also note that SAPs are one kind of practice among others that are increasingly posing challenges to the traditional distinction between research and practice, and the regulatory structures built around this distinction. Part of the reason that SAPs invoke the issues discussed above is that they are not clearly either research or routine clinical practice. Increasingly, practices which combine clinical care with data generation challenge that dichotomy. Quality improvement initiatives, for instance, often draw on data collected about routine clinical practice to mandate change (Wipke-Tevis 2001). Large patient databases or registries provide new knowledge on the safety and effectiveness of 
interventions that are in widespread use. ${ }^{15}$ These and other developments have led some to envision a breakdown of the distinction between research and clinical practice (see Largent et al 2011; Kass et al 2013; Faden et al 2013); we regard collecting data from SAPs as one further example of this blurring of research and practice.

Despite the challenges of our proposal, we believe that requiring the collection of data from SAPs is morally justified. We appreciate the moral 'pull' of compassion and the desirability of assisting those in dire medical need; however, this must be balanced by protections to the corporate goods provided by regulation. Without mandated data collection, SAPs have to potential to seriously undermine current systems for ensuring safe and effective medical interventions.

\section{References}

Abigail Alliance for Better Access to Developmental Drugs and the Washington Legal Foundation. 2003. Citizen Petition of the Abigail Alliance and the Washington Legal Foundation to the Food and Drug Administration, U.S. Dept. of Health and Human Services. Available at http://www.fda.gov/ohrms/dockets/dailys/03/Jun03/061703/03p-0274-cp00001-01vol1.pdf, accessed 25 May 2013.

${ }^{15}$ For example, registry-derived data identified the long-term dangers of metal-on-metal hip implants in Australia (TGA 2012), and in the USA informed the FDA's approval of left ventricular heart implants (FDA 2010). 
Agence Francaise de securite sanitaire des produit de santé 2007. Notice to applicants for Temporary Authorisation for Use (ATU). France: AFSSAPS.

American Society of Clinical Oncology with the Association of American Medical Colleges and the National Coalition for Cancer Survivorship. 2007. Amicus brief in the United States court of Appeals for the District court of Columbia, Case no. 04-5350.

Appelbaum, P.S., L.H Roth, and C. 1982. The therapeutic misconception: informed consent in psychiatric research. International Journal of Law and Psychiatry 5: 319-329.

Atkinson, S., A. Blanc, D. Lebel, J-F. Bussieres, B. Bailey, and A. Berard. 2007. Risk of drug interactions among children accessing drugs through Health Canada's Special Access Program. Canadian Journal of Hospital and Pharmacy 60: 114-120.

Barnabe, C., S.G Barr, and L. Martin. 2012. Infliximab therapy efficacy and persistence at a Canadian academic centre despite a change in access procedure. Clinical Rheumatology 31: 211-217.

Bates, A.K. 2008. Implementing a pre-launch named patient programme: Evidence of increased market share. Journal of Medical Marketing 8(4): 319-324. Beauchamp, T.L., and Childress, J.F. 2013. Principles of biomedical ethics seventh edition. New York: Oxford University Press.

Bedlack, R.S. 2011. Compassionate use of stem cells for ALS: Popovers and hot air. Amytrophic Lateral Sclerosis 12: 313-314.

Bender, S., L. Flicker, and R. Rhodes. 2007. Access for the terminally ill to experimental medical innovations: A three-pronged threat. American Journal of Bioethics 7(10): 3-6.

Beran, R.G., and K. Sheehan. 1996. An appraisal of the clinical use of lamotrigine under the special access scheme. Journal of Clinical Neuroscience 3(3): 239242. 
Bristol, N. 2007. Should terminally ill patients have access to phase I drugs? The Lancet 369: 815-816.

Caplan, A. 2007. Is it sound public policy to let the terminally ill access experimental medical innovations? American Journal of Bioethics 7(6): 1-3.

Carpenter, D., A.S. Kesselheim, and S. Joffe. 2011. Reputation and precedent in the Bevacizumab decision. New England Journal of Medicine 365 : e3.

Chahal, M. 2010. Off-trial access to experimental cancer agents for the terminally ill: Balancing the needs of individuals and society. Journal of Medical Ethics 36: 367-370.

Cholst, I.N. 2013. Oocyte donation and the therapeutic misconception. Fertility and Sterility 99(6): 1561-1562.

Davis, M. 2006. Should experimental therapy be made available off-study for terminally ill patients? The Lancet Oncology 7:531-533.

DiMasi, J.A., R.W. Hansen, and H. Grabowski. 2003. The price of innovation: new estimates of drug development costs. Journal of Health Economics 22: $151-185$.

Dresser, R. 2006. Investigational drugs and the constitution. Hastings Centre Report (November-December): 9-10.

Edwards, S.J.L. 2006. Restricted treatments, inducements, and research participation. Bioethics 20(2): 77-91.

Edwards, S.J.L. 2013. Ethics of clinical science in a public health emergency: Drug discovery at the bedside. American Journal of Bioethics 13(9): 3-14.

Epstein, R.M., and V. Entwistle. 2013. Capacity and shared decision-making in serious illness. In Palliative care and ethics: common ground and cutting edges, ed. T.E. Quill and F.G. Miller. Oxford: Oxford University Press.

European Community Directive 2001.83.EC. Available at

http://www.edctp.org/fileadmin/documents/ethics/DIRECTIVE_200183EC_OF_THE_EUROPEAN_PARLIAMENT.pdf, accessed 1 March 2013. 
European Community Regulation (EC) No 726/2004. Available at http://eurlex.europa.eu/LexUriServ/LexUriServ.do?uri=0J:L:2004:136:0001:0033:en:PDF, accessed 1 March 2013

Evans, S., B. Loff, and P. Cameron. 2013. Clinical registries: The urgent need to address ethical hurdles. Medical Journal of Australia 198(3): 134-135.

Faden, R., N. Kass, S.N. Goodman, P. Pronovost, S. Tunis, and T. Beauchamp. 2013. An ethics framework for a learning healthcare system: A departure from traditional research ethics and clinical ethics. Hastings Centre Report Special Report: Ethical Oversight of Learning Healthcare Systems JanuaryFebruary 2013: S16-S27.

Falit, B.P., and Gross, C.P. 2008. Access to experimental drugs for terminally ill patients. Journal of the American Medical Association 300(23): $2793-2795$. Food and Drug Administration. 2009. Expanded Access to Investigational Drugs for Treatment Use (final rule). Federal Register 74(155): 40900-40945. Food and Drug Administration. 2010. FDA Approves Left Ventricular Assist System for Severe Heart Failure Patients. Available at http://www.fda.gov/newsevents/newsroom/pressannouncements/ucm198172.htm, accessed 29 June 2013.

Food and Drug Administration. 2013. About FDA: What We do: History. Available at http://www.fda.gov/AboutFDA/WhatWeDo/History/default.htm, accessed 13 May 2013.

Ghinea, N., W.L. Lipworth, I.H Kerridge, and R.O. 2012. No evidence or no alternative? Taking responsibility for off-label prescribing. Internal Medicine Journal 42(3): 247-251.

Hamilton, E., G. Lyman, and J. Peppercorn. 2010. Availability of experimental therapy outside oncology randomized clinical trials in the United States. Journal of Clinical Oncology 28(34): 5067-5073. 
Harris, J. 2005. Scientific research is a moral duty. Journal of Medical Ethics 31(4): 242-248.

Health Canada. 2007. The Medical Devices Special Access Programme. Ottawa: Therapeutic Products Directorate.

Health Canada. 2008. Guidance document for industry and practitioners: Special access programme for drugs. Canada: Minister of Public Works and Government Services.

Hofmann, B. 2002. Is there a technological imperative in Healthcare? International Journal of Technology Assessment in Health Care 18(3): 675-689.

Institute of Medicine. 1991. Expanding Access to Investigational Therapies for HIV Infection and AIDS: Roundtable for the Development of Drugs and Vaccines Against AIDS. Washington, D.C: National Academy of Sciences.

Isbister, J., Phillips, L., Dunkley, S., Jankelowitz, G., McNeil, J., and P. Cameron. 2008. Recombinant activated factor VII in critical bleeding: Experience from the Australian and New Zealand Haemostasis Register. Internal Medicine Journal 38: 156-165.

Jacobsen, P.D., and W.E. Parmet. 2007. A new era of unapproved drugs: The case of Abigail Allliance v Von Eschenbach. Journal of the American Medical Association 297(2): 205-208.

Kass, N, R.R. Faden, S.N. Goodman, P. Pronovost, S. Tunis, and T.L Beauchamp. 2013. The research-treatment distinction: A problematic approach for determining which activities should have ethical oversight. Hastings Centre Report Special Report: Ethical Oversight of Learning Healthcare Systems January-February 2013: S4-S15.

Kelly, J.S. 2008. Experimental medicines in multiple sclerosis and compassionate use. Journal of the Royal College of Physicians Edinburgh 39: 35-37. Largent, E.A., S. Joffe, and F.G Miller. 2011. Can research and care be ethically integrated? Hastings Centre Report July-August: 37-46. 
Largent, E.A., F.G. Miller, and S.D. Pearson. 2009. Going off-label without venturing offcourse: Evidence and ethics in off-label prescribing. Archives of Internal Medicine 169(19): 1745-47.

Leonard, E.W. 2009. Right to experimental treatment: FDA new drug approval, constitutional rights, and the public's health. Journal of Law, Medicine and Ethics (Summer 2009): 269-279.

Lundh, A., S. Sismondo, J. Lexchin, O.A. Busuioc, and L. Bero. 2012. Industry sponsorship and research outcome. Cochrane Database of Systematic Reviews 12:MR000033.

Munthe, C. Precautionary principle. In International Encyclopedia of Ethics, ed. H. LaFollette. Chichester: Wiley-Blackwell.

Myerson, D. 2013. Innovative surgery and the precautionary principle. Journal of Medicine and Philosophy 38(6): 605-624.

National Prescribing Centre 2011. Prescribing Specials: Five guiding principles for prescribers. United Kingdom: NICE.

Rago, L., and B. Santoso. 2008. Drug regulation: History, present and future. In Drug Benefits and Risks: International Textbook of Clinical Pharmacology, ed. C.J. van Boxtel, B. Santoso, and I.R. Edwards, 65-77. Lansdale, PA: IOS Press.

Robertson, J.A. 2006. Controversial medical treatment and the right to health care. Hastings Centre Report 36(6): 15-20.

Ross, E. 2009. Unapproved drug use: Compassionate or cause for concern? The Lancet Neurology 8(2): 136-137.

Royal Australasian College of Physicians. 2013. The use of sustained release formulations of naltrexone in opioid dependence: Position statement. Sydney: RACP.

Schuklenk, U., and C. Lowry. 2009. Terminal illness and access to Phase 1 experimental agents, surgeries and devices: Reviewing the ethical arguments. 
British Medical Bulletin 89: 7-22.

Shaefer, G.O., E.J. Emanuel, and A. Wertheimer. 2009. The obligation to participate in medical research. Journal of the American Medical Association 302(1): $67-72$.

Shorr, A.F. 1992. AIDS and the FDA: An ethical case for limiting patient access to new medical therapies. IRB: Ethics and Human Research 14(4): 1-5.

Supreme Court of United States. 1979. Case 78-605, United States v. Rutherford. 442 U.S. 544 (1979).

Therapeutic Goods Administration. 2004. Access to unapproved therapeutic goods: Authorised Prescribers. Canberra: TGA.

Therapeutic Goods Administration. 2009. Access to unapproved therapeutic goods via the Special Access Scheme. Canberra: TGA.

Therapeutic Goods Administration. 2012. Metal-on-metal hip replacement implants: Information for general practitioners, orthopaedic surgeons and other health professionals. Available at http://www.tga.gov.au/hp/information-devices-mom-hipimplants.htm, accessed 13 April 2013.

US Court of Appeals. 2007. Case 04-5350, Abigail Alliance for Better Access to Developmental Drugs et al. v. von Eschenbach et al. En Banc Reply Brief of Appellants.

Whitfield, K., K-H. Huemer, D. Winter, et al. 2010. Compassionate use of interventions: Results of a European Clinical Infrastructures Network (ECRIN) survey of ten European countries. Trials 11(104).

Wicks, P., T. Vaughan, M. Massagli, and J. Heywood. 2011. Accelerated clinical discovery using self-reported patient data collected online and a patientmatching algorithm. Computational Biology 29(5): 411-414.

Widdows, H., and S. Cordell. 2011. Why communities and their goods matter: Illustrated with the example of biobanks. Public Health Ethics 4(1): 14-25. 
Wipke-Tevis, D.D. 2001. What is research? Journal of Vascular Nursing 19(2): 63-64.

Young, P. 2009. Expanded access to INDs. Community Oncology 6(10): 478. 


\begin{tabular}{|c|c|c|c|c|c|c|c|c|}
\hline & Name of program & $\begin{array}{l}\text { Individual/ } \\
\text { cohort of } \\
\text { patients }\end{array}$ & Requirements & $\begin{array}{l}\text { Application and } \\
\text { authorisation } \\
\text { needed }\end{array}$ & Who pays & $\begin{array}{l}\text { Data collection } \\
\text { obligations }\end{array}$ & $\begin{array}{l}\text { Informed } \\
\text { consent }\end{array}$ & $\begin{array}{l}\text { Ethics } \\
\text { committee } \\
\text { (IRB) } \\
\text { involvement }\end{array}$ \\
\hline Australia & $\begin{array}{l}\text { Special Access } \\
\text { Scheme }\end{array}$ & Individual & $\begin{array}{l}\text { Serious condition; no } \\
\text { alternative }\end{array}$ & $\begin{array}{l}\text { Authorisation } \\
\text { needed for } \\
\text { category B patients } \\
\text { from Therapeutic } \\
\text { Goods } \\
\text { Administration; } \\
\text { statutory } \\
\text { notification scheme } \\
\text { for category A } \\
\text { patients }\end{array}$ & & $\begin{array}{l}\text { AE reported to } \\
\text { Therapeutic Goods } \\
\text { Administration }\end{array}$ & $\begin{array}{l}\text { Expected } \\
\text { as part of } \\
\text { routine } \\
\text { practice }\end{array}$ & Not required \\
\hline Australia & $\begin{array}{l}\text { Authorised } \\
\text { Prescriber system }\end{array}$ & Cohort & $\begin{array}{l}\text { Clinical need; } \\
\text { justification for not } \\
\text { using other therapeutic } \\
\text { options }\end{array}$ & $\begin{array}{l}\text { Authorisation } \\
\text { needed from } \\
\text { Therapeutic Goods } \\
\text { Administration }\end{array}$ & & $\begin{array}{l}\text { AE and regular outcome } \\
\text { reporting to ethics } \\
\text { committee }\end{array}$ & Required & Required \\
\hline Austria $^{16}$ & $\begin{array}{l}\text { Named Patient } \\
\text { Use }\end{array}$ & Individual & $\begin{array}{l}\text { Serious condition; no } \\
\text { alternative; no clinical } \\
\text { trials available }\end{array}$ & No & & None & & \\
\hline Canada & $\begin{array}{l}\text { Special Access } \\
\text { Program }\end{array}$ & Individual & $\begin{array}{l}\text { Serious condition; no } \\
\text { alternative }\end{array}$ & Required & & $\begin{array}{l}\text { Practitioner must agree } \\
\text { to provide report on } \\
\text { results of use including } \\
A E\end{array}$ & Expected & Not required \\
\hline Denmark & $\begin{array}{l}\text { Compassionate } \\
\text { Use Permit }\end{array}$ & Individual & $\begin{array}{l}\text { Serious condition; no } \\
\text { alternative }\end{array}$ & $\begin{array}{l}\text { To Danish } \\
\text { Medicines Agency }\end{array}$ & & $\begin{array}{l}\text { AE and safety and } \\
\text { efficacy data reported }\end{array}$ & $\begin{array}{l}\text { Consent } \\
\text { to }\end{array}$ & Not required \\
\hline
\end{tabular}

${ }^{16}$ Austria was reported to be in the process of drafting regulations for cohort programs in 2010 (Whitfield et al 2010). 


\begin{tabular}{|c|c|c|c|c|c|c|c|c|}
\hline & & & & & & $\begin{array}{l}\text { to Danish Medicines } \\
\text { Agency }\end{array}$ & $\begin{array}{l}\text { disclose } \\
\text { health } \\
\text { data } \\
\text { required }\end{array}$ & \\
\hline France & $\begin{array}{l}\text { Nominative } \\
\text { Temporary } \\
\text { Authorisation for } \\
\text { Use }\end{array}$ & Individual & $\begin{array}{l}\text { Serious condition; no } \\
\text { alternative; positive } \\
\text { risk-benefit ratio }\end{array}$ & $\begin{array}{l}\text { To French } \\
\text { Medicines Agency } \\
\text { (AFSSAPS) }\end{array}$ & $\begin{array}{l}\text { Hospital/ } \\
\text { national } \\
\text { insurance } \\
\text { system }\end{array}$ & $\begin{array}{l}\text { AE reporting managed } \\
\text { by AFSSAPS }\end{array}$ & $\begin{array}{l}\text { Expected } \\
\text { as for } \\
\text { routine } \\
\text { practice }\end{array}$ & Not required \\
\hline France & $\begin{array}{l}\text { Cohort Temporary } \\
\text { Authorisation for } \\
\text { Use }\end{array}$ & Cohort & $\begin{array}{l}\text { Serious condition; no } \\
\text { alternative; positive risk } \\
\text { benefit ratio; medicine } \\
\text { at advanced stage of } \\
\text { development; no } \\
\text { clinical trials available } \\
\text { for patients; company } \\
\text { must commit to } \\
\text { pursuing approval in } \\
\text { specified timeframe }\end{array}$ & $\begin{array}{l}\text { To French } \\
\text { Medicines Agency } \\
\text { (AFSSAPS) }\end{array}$ & $\begin{array}{l}\text { Hospital/ } \\
\text { national } \\
\text { insurance } \\
\text { system }\end{array}$ & $\begin{array}{l}\text { AE reporting managed } \\
\text { by company; treatment } \\
\text { protocol specifying data } \\
\text { collection procedures; } \\
\text { safety and efficacy data } \\
\text { reported to AFSSAPS }\end{array}$ & Required & Not required \\
\hline Germany & $\begin{array}{l}\text { Compassionate } \\
\text { use }\end{array}$ & Individual & $\begin{array}{l}\text { Serious condition; no } \\
\text { alternative }\end{array}$ & No & $\begin{array}{l}\text { Company } \\
\text { must } \\
\text { provide }\end{array}$ & $\begin{array}{l}\text { AE reporting as in } \\
\text { clinical trials; safety and } \\
\text { efficacy data reported } \\
\text { to regulatory authorities }\end{array}$ & Required & Not required \\
\hline Ireland & $\begin{array}{l}\text { (No separate } \\
\text { program but can } \\
\text { be done under } \\
\text { clinical trial } \\
\text { regulations) }\end{array}$ & & $\begin{array}{l}\text { Product between phase } \\
\text { III trials and } \\
\text { authorisation }\end{array}$ & $\begin{array}{l}\text { Statutory } \\
\text { Notification } \\
\text { System; to Irish } \\
\text { Medicines Board }\end{array}$ & & & & \\
\hline Italy & $\begin{array}{l}\text { Therapeutic Use of } \\
\text { Drug Undergoing } \\
\text { Clinical Trial }\end{array}$ & Individual & $\begin{array}{l}\text { Serious condition; no } \\
\text { alternative }\end{array}$ & $\begin{array}{l}\text { To ethics } \\
\text { committee }\end{array}$ & Patient & $\begin{array}{l}\text { No specific rules but } \\
\text { expected to be same as } \\
\text { for routine practice (AE } \\
\text { reporting; }\end{array}$ & Required & Required \\
\hline
\end{tabular}




\begin{tabular}{|c|c|c|c|c|c|c|c|c|}
\hline & & & & & & pharmacovigilance) & & \\
\hline Spain & $\begin{array}{l}\text { Compassionate } \\
\text { Use }\end{array}$ & Individual & $\begin{array}{l}\text { Serious condition; no } \\
\text { alternative; company } \\
\text { must be awaiting } \\
\text { approval; no clinical } \\
\text { trials available }\end{array}$ & Required & & $\begin{array}{l}\text { Safety and efficacy data, } \\
\text { clinical report, and AE to } \\
\text { regulatory authority }\end{array}$ & Required & Required \\
\hline UK & $\begin{array}{l}\text { Manufacture/ } \\
\text { Import and Supply } \\
\text { of unapproved } \\
\text { good ('specials') }\end{array}$ & Individual & $\begin{array}{l}\text { No alternative; bona } \\
\text { fide unsolicited order; } \\
\text { product formulated in } \\
\text { accordance with the } \\
\text { requirement of a } \\
\text { registered doctor/ } \\
\text { dentist }\end{array}$ & $\begin{array}{l}\text { Notification } \\
\text { scheme in use to } \\
\text { MHRA }\end{array}$ & & $\begin{array}{l}\text { AE reporting to MHRA; } \\
\text { essential records must } \\
\text { be kept }\end{array}$ & & Not required \\
\hline USA & $\begin{array}{l}\text { Emergency Use } \\
\text { IND } \\
\text { (Investigational } \\
\text { new drug) }\end{array}$ & $\begin{array}{l}\text { Individual } \\
\text { use, } \\
\text { smaller } \\
\text { cohorts }\end{array}$ & $\begin{array}{l}\text { Serious condition; no } \\
\text { alternative; no clinical } \\
\text { trial available }\end{array}$ & $\begin{array}{l}\text { Notification } \\
\text { Scheme to FDA }\end{array}$ & $\begin{array}{l}\text { Company } \\
\text { must } \\
\text { provide } \\
\text { free or cost } \\
\text { recovery } \\
\text { only }\end{array}$ & $\begin{array}{l}\text { Physician must supply } \\
\text { report on treatment } \\
\text { outcomes to FDA }\end{array}$ & Required & Required \\
\hline USA & Treatment IND & $\begin{array}{l}\text { Larger } \\
\text { cohorts }\end{array}$ & $\begin{array}{l}\text { Serious condition; no } \\
\text { alternative; IND trial } \\
\text { underway or } \\
\text { completed; company } \\
\text { must be pursuing } \\
\text { approval }\end{array}$ & $\begin{array}{l}\text { FDA must approve } \\
\text { treatment protocol }\end{array}$ & $\begin{array}{l}\text { Company } \\
\text { must } \\
\text { provide } \\
\text { free or cost } \\
\text { recovery } \\
\text { only }\end{array}$ & $\begin{array}{l}\text { Physician must supply } \\
\text { report on treatment } \\
\text { outcomes to FDA }\end{array}$ & Required & Required \\
\hline
\end{tabular}

